Editorial

\title{
Message from the President
}

It is a common practice to have the President of Sociedade de Psiquiatria do Rio Grande do Sul (SPRS) address the readers of the Journal of Psychiatry of Rio Grande do Sul (Rev Psiquiatr RS), the official publication of the Society, at the beginning of a new administration. I was part of the Editorial Board in a few administrations, and I have a special interest and affection for it.

The SPRS is an institution that gathers psychiatrists with a wide range of specialties, interests and practices. Maintaining and respecting this diversity are essential commitments of this administration.

The Editorial Board will once again be composed of two editors. Our colleague Flávio Shansis remains as one of the editors. His characteristics of creativity, enthusiasm and scientific knowledge are widely known by everyone. This assures the continuity of the journal, due to its complex functioning. Aiming at maintaining the diversity, I have invited our colleague Carmem Emília Keidann to be the other editor. In addition to her professional and personal qualities, Carmem has a vast experience in journals related to our area: she was part of the Editorial Board of this journal in previous administrations. She also belonged to the Editorial Board of Revista de Psicanálise da Sociedade Psicanalítica de Porto Alegre and was the editor of Revista Brasileira de Psicoterapia.

Following a tendency that was already taking place during the 2004-2005 administration, Flávio and our colleague Jacó Zaslavsky created an efficient and productive coordination that made the journal reach a level of development that currently characterizes it as one of the main national publications in the area of mental health. Special thanks to Jacó for his determined, entrepreneurial and resolute personality in exercising his editorial position. 
Regular publication, national distribution, financial health thanks to our advertising partners and the support of CNPq make SPRS and all psychiatrists from our state proud of this journal which is ours. Since it is a major source of scientific knowledge, I would like to encourage our members to keep an active participation, either as authors of scientific, research or clinical experience articles, or doing the important activity of evaluating articles.

With this new team of editors and a renewed and plural Editorial Board, I have the conviction that our journal will keep on being a vehicle for the national scientific production based on different specialties, interests and practices.

Laís Knijnik

President, Sociedade de Psiquiatria do Rio Grande do Sul 